\title{
Should we be worried about sexual transmission of Zika and other arboviruses?
}

\author{
Alfonso J. Rodriguez-Morales ${ }^{1,2}$, Luisa Alejandra Espinoza-Flores ${ }^{3,4}$ \\ ${ }^{1}$ Colombian Collaborative Network on Zika (RECOLZIKA), Pereira, Colombia \\ ${ }^{2}$ Public Health and Infection Research Group, Faculty of Health Sciences, Universidad Tecnológica de Pereira, Pereira, Colombia \\ ${ }^{3}$ Hospital Roatan, Thicket Mouth Rd, Coxen Hole, Roatan Islands, Honduras \\ ${ }^{4}$ Faculty of Medical Sciences, Universidad Nacional Autónoma de Honduras, Tegucigalpa, Honduras
}

In relation to the interesting review by Korzeniewski et al. [1] concerning the Zika virus and the discussions of Kuna and Gajewski [2] as well from Joob and Wiwanitkit [3], we also would like to highlight some new facts concerning the sexual transmission of arboviruses that have arisen very recently $[4,5]$. Zika fever is an acute infectious disease caused by the Zika virus (ZIKV), a flavivirus discovered in Uganda in 1947. It has increasingly become a disease with a relevant interest, since its very high transmissibility has facilitated its spreading among several regions across the world such as South America, Central America, Asia, Oceania, Southern Europe and Southern United States as well its consequences (e.g. Guillain-Barré syndrome and congenital disease leading to birth defects).

Recent evidence has demonstrated that ZIKV can be acquired by vector-borne transmission through the female Aedes mosquitoes (e.g. A. aegypti, A. albopictus), blood transfusion, from mother to foetus in pregnancy, and by sexual contact [1], among other potential ways recently demonstrated [6]. The sexual transmission has been suspected when cases of patients that returned to the United States from endemic areas have been reported, developing later on symptoms of Zika fever, as well as their sexual partners with no travel history to endemic areas, after they had unprotected sexual intercourse with their respective infected couples [1-4]. Furthermore, in the last years, some studies reported that the virus can be found in serum, saliva, urine and semen, confirming the theory that ZIKV sexual transmission is already a proven fact [1-4].

For these reasons, the Centers for Disease Control and Prevention (CDC) as well as the World Health Organisation (WHO) recommend to have safe sexual practices 6 months after the exposure only or the onset of symptoms [1-4], although
Joob and Wiwanitkit [3] stated that safe sexual practices with conventional condoms is now questioned, due to the very small size of the virus $(40 \mathrm{~nm})$ and consequently, is able to overpass the condom pores. In addition, they also mentioned that ZIKV is an important threat in the assisted reproductive technology since the semen of the donators is not routinely checked.

Given this scientific evidence, the global health efforts are oriented nowadays in investigate and prevent the ZIKV sexual transmission, paying less attention to the possibility that other arboviruses might have the capacity to be sexually transmitted. This is concerning if the findings of a recent paper can be reproducible in other studies [5]. This is the case of chikungunya virus (CHIKV). Bandeira et al. [5] published a case report of a 25-year-old male patient with chikungunya fever in which CHIKV was isolated in urine and semen after a prolonged period of time after the onset of symptoms. Although they not performed cytopathic assays for CHIKV, this finding must be further investigated; such findings suggest that the probability of CHIKV sexual transmission cannot be ruled out at all.

Hence, we would like to encourage the international scientific community to have this case report into consideration to perform further investigations, in order to prevent a potential new mode of transmission of $\mathrm{CHIKV}$, also considering that endemic areas for ZIKV tends to overlap with CHIKV, but in CHIKV-only endemic areas this should be on the epidemiological thinking in order to add this as a possibility for prevention.

\section{REFERENCES}

1. Korzeniewski K, Juszczak D, Zwolińska E. Zika - another threat on the epidemiological map of the world. Int Marit Health. 2016; 67(1): 31-37, doi: 110.5603/IMH.2016.0007, indexed in Pubmed: 27029927. 
2. Kuna A, Gajewski M. Prevention of sexual transmission of Zika virus. Int Marit Health. 2016; 67(3): 179-180, doi: 10.5603/ IMH.2016.0033, indexed in Pubmed: 27681219.

3. Joob B, Wiwanitkit V. Sexual transmission of Zika virus: what is the issue for awareness? Int Marit Health. 2016; 67(4): 260, doi: 10.5603/IMH.2016.0046, indexed in Pubmed: 28009384.

4. Patiño-Barbosa AM, Medina I, Gil-Restrepo AF, et al. Zika: another sexually transmitted infection? Sex Transm Infect. 2015; 91(5): 359, doi: 10.1136/sextrans-2015-052189, indexed in Pubmed: 26113729.
5. Bandeira AC, Campos GS, Rocha VF, et al. Prolonged shedding of Chikungunya virus in semen and urine: A new perspective for diagnosis and implications for transmission. IDCases. 2016; 6: 100-103, doi: 10.1016/j.idcr.2016.10.007, indexed in Pubmed: 27882301.

6. Rodriguez-Morales AJ, Bandeira AC, Franco-Paredes C. The expanding spectrum of modes of transmission of Zika virus: a global concern. Ann Clin Microbiol Antimicrob. 2016; 15: 13, doi: 10.1186/s12941-016-0128-2, indexed in Pubmed: 26939897. 